\title{
E-Devlet Adaptasyonunda Etkili Olan Faktörlerin Belirlenmesine İlişkin Ampirik Bir Araştırma: Yalova Örneği
}

\author{
An Empirical Research About Determining the Factors Effecting E-government \\ Adoption: Evidence from Yalova
}

İkram DAŞTAN' ${ }^{1}$, Özlem EFILOĞLU KURT ${ }^{2}$

\begin{abstract}
ÖZET
$\mathrm{Bu}$ araştırma ile vatandaşların e-devlet adaptasyonunu etkileyen kritik faktörleri belirlemek amaçlanmaktadır. Araştırma kapsamında e-devlet hizmetleri kullanan 586 kullanıcı ile yüz yüze anket yapılarak bulgular elde edilmiştir. Analizler sonucunda e-devlet kabulüne etki edebilecek çeşitli faktör grupları ile e-devlet adaptasyonu arasındaki ilişkiler istatistiksel olarak ortaya konmuştur. Kaynakların kullanılabilirliği, algılanan fonksiyonel fayda ve algılanan hizmet yanıtının e-devlet adaptasyonunda pozitif bir etki oluşturdukları görülmüştür. Ayrıca algılanan hizmet yanıtı ve kaynakların kullanılabilirliğinin de fonksiyonel faydayı olumlu yönde etkilediği görülmüştür.
\end{abstract}

Anahtar Kelimeler: e-devlet, e-devlet adaptasyonu

\section{GíRiş}

Bilgi ve iletişim teknolojileri ilk kullanılmaya başlandıkları 1960'lardan beri kamu sektöründe kullanılmaktadır. İnternetin ortaya çıkışı ve yaygınlaşması ile bu kullanım yerini "e-devlet" kavramına bırakmıştır. Hızla gelişen bir alan olarak e-devlet kavram ve teorilerini farklı disiplinlerden araştırmacılar, farklı bakış açılarıyla incelemeye devam etmişlerdir (Heeks, 2005; Joseph, 2013; Snead ve Wright, 2014). Bununla birlikte vatandaş ve devletlerin beklentileri teknolojik gelişmelere paralel olarak değişmiştir. Bu değişim sırasında devletler birçok hizmeti elektronik ortamda sunarak etkin bir dijital altyapı oluşturmuşlardır. Devlet hizmetlerinin elektronik ortama aktarılmasının verimliliği olumlu yönde etkilemesine bağlı olarak e-devlet hizmetleri gelişmiş ve gelişmekte olan ülkelerde kalııı gündem

\begin{abstract}
In this study, a detailed review of the extant literature is provided, and model propositions and tested measures which were previously formed for developing and developed countries are investigated. The present research employs a face-to-face survey method with 586 partipants. In the data collection process, statements formed from previously tested measures in the field and scales including demographic factors are used. It is revealed that the availability of resources, perceived functional benefit and perceived service response have a positive affect on the acceptance of e-government. Moreover, the results reveal that perceived service response and availability of resources positively effect the functional benefit.
\end{abstract}

Keywords: e-government, e-government adoption maddelerinden biri olmuştur (Davison ve diğerleri, 2005). Politika yapıcılar vatandaşların ve işletmelerin ihtiyaçlarını analiz ederek basit ve sık kullanılan hizmetlerin elektronik ortamlara aktarılmasının verimliliği artıracağını kabul etmişlerdir. Böylece devlet hizmetlerinin elektronik ortamlarda yürütülmesini içeren birçok politika geliştirilmiştir (Foley, 2005; Tung\&Rieck, 2005). Ancak yapılan bu yatırımların etkinliğinin önemi kadar vatandaşların bu hizmetlere erişimleri ve yaklaşımları da büyük önem taşımaktadır. Kurumlar tarafından hizmetler bir taraftan elektronik ortama aktarılırken diğer taraftan bu hizmetlere erişim, kullanım isteği, kullanım becerisi, farkındalık, algılanan fonksiyonel fayda, kaynakların kullanılabilirliği, e-devlet hizmetlerine duyulan güven, e-devlet kapsamında araştırılması gereken konular olarak araştırmacıların ilgisini 
çekmeye devam etmiştir. Bu çerçevede vatandaşların/ kullanıcıların teknolojiye adaptasyonu gündeme gelmiş ve "e-devlet adaptasyonu" kavramı literatürde yerini almıştır.

$\mathrm{Bu}$ araştırmanın temel amacı Yalova özelinde kamusal hizmet dönüşümünün önemli bir göstergesi olan e-devlet uygulamalarına vatandaşların adaptasyonunda etkili olan en temel faktörlerin belirlenmesidir. Bu araştırmada geniş bir literatür taraması yapılarak daha önce gelişmiş ve gelişmekte olan ülkeler için oluşturulmuş model önerileri ve test edilmiş ölçekler incelenmiştir.

\section{E-DEVLET KAVRAMI}

Heeks ve Bailur (2007)'a göre e-devlet teriminin geçmişi 1997 yılına dayanmaktadır. Bu tarihte Amerika Birleşik Devlerinde gerçekleştirilen ve federal hizmetlerin sunumunda Ulusal Performans Değerlendirmesi (National Performance Review) başlıklı reform girişiminin raporlarında ilk olarak e-devletin rolüne güçlü bir vurgu yapılmıştır (Sobacı,Yıldız, 2012). Rhoda (2013) araştırmasında e-devlet alanının görece yeni olduğunu ve çeşitli araştırma olanakları sunduğunu belirtmiştir. Ayrıca e-devlet projelerinin gelişimini etkileyen teknik, ekonomik, sosyal, organizasyonel ve politikfaktörlerin olduğundan bahsetmiştir.

E-devletin kabul görmüş evrensel bir tanımı yoktur (Halchin, 2004). Bu alanda yapılan tartışma ve araştırmalara bakıldığında dünya genelinde e-devletin farklı şekillerde kavramsallaştırıldığı görülmektedir. Tanımlamalar sadece anlamsal boyutta değil, e-devletin öncüllerini yansıtma noktasında ulusal ve uluslararası düzeylerde de farklılık arz etmektedir (Şahin, 2007). Genel olarak e-devlete ilişkin tanımlarda teknolojik araçlar, vatandaşlar ve paydaşlar, devletin aktif rolü ve belirlenen amaçlar, uygulama alanları gibi unsurların birine veya birkaçına yer verildiği görülmektedir (Sobacı, Yıldız, 2012). E-devlet kurum ve kuruluşların kendi aralarında olan ilişkilerinin yanı sıra vatandaş ve iş dünyası ile olan ilişkilerinde de elektronik araçları en etkin düzeyde kullanarak, geleneksel devlet hizmetlerinin elektronik ortama aktarılmasını, daha etkin, yalın, katılımcı, ve şeffaf yönetim anlayışııın benimsenmesini, bürokratik engellerin azaltılması ile iş akış süreçlerinin kısaltılmasını ve kurumsal iletişimin büyük bir oranda elektronik ortamda sürdürülmesini olanaklı kılan devlet modelidir (Odabaş, 2009).
E-devlet elektronik bilgi ve iletişim teknolojileri aracılığıyla kamu hizmetlerinin daha hızlı etkin şeffaf bir biçimde vatandaşlara, özel kuruluşlarına ve diğer kamu kurumlarına düşük maliyetle sunulmasını ifade etmektedir (Şahin, 2007). Lu (2006) e-devleti, devlet ile iş dünyası, vatandaşlar ve diğer devletler arasındaki etkinliği, verimliliği, şeffaflığı ve hesap verilebilirliği sağlamak için bilişim teknolojilerinin kullanılması şeklinde tanımlamıştır. Bir başka tanımıyla e-devlet bilgi ve iletişim teknolojileri kullanılarak kamu yönetiminin yerine getirilmesine yardımcı olan bilgi sistemidir (Tung ve Rieck, 2005). Bir başka tanımda ise e-devlet, "devletin sunduğu hizmetlerde bilişim teknolojilerinin kullanılması" şeklinde tanımlanmaktadır (Carter ve Belanger 2005). Tüm bunlara ek olarak e-devlet sadece mevcut devlet fonksiyonlarını elektronik ortama taşıma süreci olmayıp gerekli olanları değiştirmek, yenilerini koymak ve mevcutlarda iyileştirmeler yapmaktır (Naralan, 2008). Araştırmacıların yapmış olduğu tüm bu tanımlardan yola çıkarak e-devleti "devletin vatandaşlarına karşı yerine getirmekle yükümlü olduğu görev ve hizmetler ile vatandaşın devlete karşı yerine getirmekle yükümlü olduğu işlemlerin elektronik ortamda güvenli bir şekilde yapılması" şeklinde ifade etmek mümkündür.

Andersen ve Henriksen (2005) yaptıkları bir araştırmada 1998-2003 yılları arasında e-devlet hakkında yazıımış 110 makaleyi incelemiş, bu makalelerin \%24'ünün kavramsal boyut, \%18'inin teknoloji yayılımı, $\% 34$ 'ünün e-hizmet ve $\% 25^{\prime}$ inin e-demokrasi hakkında olduğunu tespit etmişlerdir. Bir diğer araştırmada Dwivedi (2009), 2007 ve 2008 yıllarında Transforming Government: People, Process and Policy'de (TGPPP) yayınlanan 41 makaleyi incelemiş, e-devlet konusunda yapılan araştırmaların çoğunun kavramsal boyutu örnek olayla incelediğini tespit etmiştir. E-devlet çalışmalarını analiz etmeyi amaçlayan bu araştırmaya göre TGPPP yazarlarının son iki yılda çoğunlukla analitik, tanımlayıcl, teorik ve kavramsal araştırma yöntemlerini kullanmıştır. Ortaya çıkan bir diğer araştırma sonucu da alana katkı yapan araştırmacıların büyük çoğunluğunun bilgi sistemleri altyapısına sahip olanlar olduğu, bunları da iş, bilgisayar bilimi ve bilgi teknolojileri altyapısına sahip olanların izlediğidir. 1999-2005 yılları arasında yayınlanan 73 makaleyi kapsayan bir diğer araştırmada ise e-devletin karakteristikleri ve belirleyicileri tespit edilerek çok boyutlu bir model önerilmiştir (Luna-Reyes, Gil-Garcia, Romero, 2012). 
Yaşamın her alanında olduğu gibi etkileşim, e-devletin paydaşları açısından da üzerinde durulması gereken bir konudur. Devletin vatandaşlar, iş dünyası, kamu çalışanları ve diğer kamu kurumlarıyla olan etkileşimi çift yönlüdür. Elektronik ortamdaki bu etkileşim arz ve talep boyutlu olarak ortaya çıkmaktadır. Devlet tarafından vatandaşlara ve diğer kurum ve kuruluşlara yönelik olarak sağlanan elektronik etkileşim arz boyutunu, vatandaşlar ve diğer kurum ve kuruluşlar tarafından devlete yönelik gerçekleştirilen elektronik etkileşim ise talep boyutunu oluşturmaktadır (Şahin ve diğerleri, 2014). E-devlet uygulamalarının, vatandaşların kamu hizmetlerine ilişkin bilgi kaynaklarına rahatlıkla ulaşmaları, süreçlerin ve işlem basamaklarının azaltılması yoluyla zamandan tasarruf sağlayarak işlemlerin çok hızıı bir şekilde yürütülmesine imkân sağlamaktadır (Ertaş, 2014). E-devlet hizmetlerinin büyük fiziksel mekânlara ihtiyaç duymaması, hatta çalışanların ev-ofis şeklinde kendi evlerinden sisteme bağlanarak işlerini yapabilmeleri, ekonomik anlamda kaynak israfını önleyerek önemli bir tasarruf kalemi oluşturacaktır. Bu temel yararının yanında e-devletin temel fonksiyonu web tabanlı bilgi ve iletişim teknolojileri yoluyla devlet ve vatandaş arasında iletişim sağlamaktır (Evans ve Yen, 2006). E-devlet ile ulaşılmak istenen amaç; işlemlerin ve iletişimin sadece elektronik ortama taşınması değil kurumsal faaliyetlerin şeffaflaştırıması, kamusal alanda kullanıc kaynaklı hataların azaltılması, kaynakların etkin kullanımı ve daha etkileşimli bir yönetim tarzı ile vatandaşın devlet ile ilişkilerinde daha etkin bir rol almasının sağlanmasıdır. E-devletin gelişimi sadece devletin bilgiyi sağlama yollarının, hizmet alımının ve vatandaşlarla ilişkilerinin değişmesi değil aynı zamanda devlet stratejilerinin yapıtaşı olmaya başlaması bakımından önemli bir girişimdir (Zhang, Xu ve Xiao, 2014). Devletlerin bütün vatandaşlarının e-devlet stratejilerinin bir parçası olabilmesi için bilgi ve iletişim teknolojilerinin kullanılmasına imkân sağlayan stratejileri göz önünde bulundurmaları gerekmektedir (Murru, 2003).

\section{E-DEVLET ADAPTASYONU KAVRAMSAL ÇERÇEVE}

E-devlet kavramına ilişkin literatürün yanı sıra e-devlet adaptasyonu da oldukça ilgi gören bir konudur. Literatürde e-devlet adaptasyonu konusundaki araştırmalar gelişmiş ve gelişmekte olan ülkelerde işletmelerin ya da vatandaşların adaptasyonu şeklinde farklılaşmakta ve e-devlet adaptasyonunu olumlu ve olumsuz etkileyen faktörler incelenmektedir (Tung ve Rieck, 2005; Lean, Zailani, Ramayah ve Fernando, 2009; Shareef, Kumar, Kumar ve Dwivedi, 2011;Al-zoubi, Sam ve Eam, 2011, Rokhman, 2011; Elbahnasawy, 2014). Heeks (2005)'e göre yayılım süreci henüz globalleşememiş ve bu yayılım Amerika, İngiltere, Kanada ve Singapur gibi gelişmiş ülkelerde hızlı olurken gelişmekte olan ülkelerde oldukça yavaş gerçekleşmiş ve gerçekleşmektedir (Tung ve Rieck, 2005; Heeks, 2005; Snead ve Wright, 2014; Rokhman, 2011).

E-devlet adaptasyonu konusunda yapılan araştırmalarda (CarterveWeerakkody,2008; Warkentin, Pavlouve Rose, 2002; Carter and Belanger, 2005; AlAwadhi ve Morris, 2008) kullanılan model ve teoriler ağırlıklı olarak Teknoloji Kabul Modeli (Davis, 1989), Yenilik Yayılımı Teorisi (Rogers, 2003) ve Birleştirilmiş Teknoloji Kabul ve Kullanımı Teorisidir (Venkatesh, Morris, Davis ve Davis, 2003; Carter ve Weerakkody, 2008). Bu teorileri esas alarak yapılan araştırmalara dayalı literatürdeki bazı araştırmalardan bahsetmek mümkündür. Zhao ve Khan (2013) vatandaşların e-devlet hizmetlerini kullanmalarını etkileyen daha önce Amerika'da test edilmiş bir modeli, Arap dünyasında e-devlet alanında önemli bir lider olan Birleşik Arap Emirlikleri'nde uygulamışlardır. Model teknoloji kabul modeli temelinde, güven ve bilgisayar öz-yeterlilik olmak üzere üç temel bileşenden oluşmaktadır. Araştırmada Amerika'dakinden farklı olarak davranışsal eğilimin vatandaşların kültürel bağlamından etkilendiklerini öne sürmüşlerdir. Ayrıca vatandaşların davranışsal eğilim ve e-devlet adaptasyonunu etkileyen faktörleri belirli bir kültürel perspektiften açıklamaya çalışmışlardır. Araştırma bulguları devletlerin, vatandaşların e-devlet hizmetlerini anlama düzeylerini geliştirmek için etkin stratejiler geliştirmelerine yardımcı olmakta aynı zamanda da kültürler arası e-devlet adaptasyonunu güçlendirmek için araştırmalara hazırlık yapma imkânı sunmaktadır. Bir başka araştırmada Alomari (2014) bir orta doğu ülkesi olan Ürdün'de yaptığı araştırmasında vatandaşların bir e-devlet projesinin başarısının belirlenmesinde önemli rol oynadığını belirtmektedir. Araştırmayı diğer araştırmalardan farklı kılan ise internete duyulan güven, web sitesi tasarımı, dini inançlar, internet ve bilgisayar becerilerine güven, algılanan fayda, görece avantaj ve karmaşıklık gibi faktörlerin yanı sıra dedikodu, değişime direnç ve iltimas faktörlerinin de 
araştırmaya dahil edilmiş olmasıdır. Araştırma aynı zamanda e-devlet adaptasyonu ile ilgili kavramların belirlenmesinde Ürdün vatandaşlarının sosyal uyumunu da göz önünde bulundurmasının önemine vurgu yapmaktadır. E-devlet adaptasyonunu inceleyen bir başka araştırmada ise Kamboçya'da yapılmıştır. Teknoloji Kabul Modeli temel alınarak kavramsal bir yapısal model oluşturulmuş ve model yapısal eşitlik modeli kullanılarak test edilmiştir. Araştırmaya göre algılanan fayda, görece avantaj ve güven kullanıcı adaptasyonunda önemli ölçüde bir etkiye sahiptir. Algılanan fayda aynı zamanda öznel normlar, imaj, çıktı kalitesi ve algılanan kullanım kolaylığı tarafından doğrudan etkilenmektedir. (Sang, Lee, ve Lee, 2010). Yine Rehman, Esichaikul ve Kamal (2012) Pakistan'da vatandaşların e-devlet hizmetlerine adaptasyonunu etkileyen kritik faktörleri belirlemek için yaptıkları bir araştırmada, ilgili literatür taraması sonucunda devlet memurları, akademisyenler ve yazılım mühendislerinden görüş alarak kavramsal bir model oluşturmuşlardır. Uzmanlardan alınan görüşlere göre farkındalık, internete duyulan güven ve devlete duyulan güven, Pakistan toplumunda önemli değişkenlerdir. Yapılan araştırma sonuçlarına göre ise farkındalık, vatandaşların e-devlet hizmetlerini kullanma eğilimlerini etkileyen önemli bir faktördür. Bilgi kalitesi de bir devlet sitesinden bilgi alırken önemli bir değişken olarak ortaya çıkmıştır. Algılanan kullanım kolaylığı, hizmet kalitesi ve işlem güvenliği ise vatandaşların devlet ile ilgili işlemlerini gerçekleştirme eğilimlerini etkileyen önemli faktörlerdir. Bir başka Asya ülkesi olan Endonezya'da 751 internet kullanıcısıyla gerçekleştirdiği araştırmasında Rokhman (2011) görece avantaj, uyumluluk, kullanım kolaylığı ve imaj değişkenlerinin vatandaşların e-devlet hizmetlerini kullanma eğilimlerini tahmin etmede etkili olduğunu belirtmiştir. Ayrıca araştırmasında 45 milyon internet kullanıcısının bulunduğu Endonezya'da hem merkezi hem yerel anlamda e-devlet hizmetlerinin iyileştirilmesinin vatandaşlarca beklendiğini vurgulamıştır. Lau ve diğerleri (2008) ise Latin Amerika ülkelerinden Brezilya, Meksika ve Arjantin'de e-devlet adaptasyonunu incelemişlerdir. İlk aşamada kavramsal bir çerçeve belirleyerek bölgedeki 17 ülke arasından nüfusları, internet servis sağlayıcı penetrasyonu ve internet kullanıcılarının sayılarını da göz önünde tutarak en büyük üç tanesini seçmişlerdir. Dünya Bankası raporlarından elde ettikleri verileri analiz ederek yaptıkları araştırma ile az gelişmiş ülkelerde yapılmış e-devlet çalışmalarındaki boşluğun doldurulmasını amaçlamışlardır.

Amerika kıtası merkezli yapılan araştırmalardan birinde Carter (2008) en etkili adaptasyon faktörlerini belirlemek amacıyla yaptığı araştırmada algılanan fayda, internete duyulan güven, önceki e-devlet hizmetinin kullanımı, algılanan kullanım kolaylığı değişkenlerinin bir e-devlet hizmetinin kullanım eğilimini önemli ölçüde etkilediğini belirtmektedir. Araştırmanın en göze çarpan bulgusu algılanan faydanın e-devlet adaptasyonunu tahmin etmede en önemli faktör oluşudur. Bu faktörün tek başına kullanma eğilimin varyansının \%78'ini açıkladığı görülmektedir. Araştırmanın en önemli sınırlıığı Amerika'da sadece bir eyalette yapılmış olmasıdır. Yazar araştırmasında bu sınırlılığı aşmak için diğer eyaletlerde ve diğer ülkelerde de araştırmanın tekrarlanabileceğini vurgulamıştır. Kanada'da yapılan bir araştırmada ise e-devlet adaptasyonunu etkileyen faktörler geniş bir literatür taraması sonucunda belirlenmeye çalışılmıştır. Araştırmaya göre algılanan farkındalık, kaynakların kullanılabilirliği, bilgisayar öz-yeterliliği, algılanan kullanılabilirlik, çoklu dil opsiyonu, algılanan bilgi kalitesi, algılanan güven ve algılanan fonksiyonel fayda ve algılanan imajın e-devlet adaptasyonunu etkileyen kritik faktörler olduğu belirlenmiştir (Shareef ve diğerleri 2011). Amerika ve Çin'de yapılan bir araştırmada ise gelişmiş ve gelişmekte olan ülkeler arasında e-devletin uygulanması konusunda bir karşılaştırma yapılmıştır. Araştırmada dünya nüfusunun \%80'inin yaşadığı Amerika, Kanada, Birleşik Krallık ve Avustralya gibi gelişmiş ülkelerin e-devlet hizmetlerinde lider bir konumda oldukları vurgulanmıştır. Geliş̧miş ve gelişmekte olan ülkelerdeki temel farklılıklar ise tarih ve kültür, teknik eleman, teknik alt yapı, vatandaşların teknoloji okuryazarlığı ve devlet çalışanlarının teknoloji okul yazarlığı şeklinde sınıflandırılmıştır (Chen ve diğerleri, 2007). Yine benzer bir araştırma gelişmiş ve gelişmekte olan ülke bağlamında Finlandiya ve Suudi Arabistan'ı incelenmiştir. Her iki ülkede de etkili olan en önemli faktörler sosyal, kültürel, politik faktörler ve kamu sektörü düzenlemeleridir. Ayrıca bir e-devlet programını uygulamak için güçlü bir altyapının yanı sıra sosyal ve kültürel değişimlerin önemi de vurgulanmıştır. Araştırmaya göre e-devlet politik, kültürel ve dini faktörler gibi çeşitli faktörlerden etkilenmektedir. Dolayısıyla bir e-devlet sisteminin başarılı bir şekilde uygulanması isteniyorsa, özellikle gelişmekte olan ülkelerde bu faktörler göz ardı edilmemeli ve 
dikkatlice analiz edilmelidir (Nawafleh, Obiedat ve Harfoushi, 2012).

Ülkemizde de e-devlet adaptasyonunu farklı yönleriyle ele alan çalışmalar mevcuttur. Bardakçı, Şahin ve Taşpınar (2013) Konya ilinde e-devlet uygulamalarını en az bir kez kullanmış olan vatandaşlarla yaptıkları araştırmada güven değişkenine vurgu yapmışlardır. Araştırmada güven değişkeninin vatandaşların e-devlet uygulamalarını kullanmaya devam etme eğilimleri üzerindeki etkisi incelenmiş ve e-devlet uygulamalarına duyulan güvenin kullanma eğilimlerini etkilediği belirlenmiştir. Yasin ve arkadaşları (2013) e-devlet uygulamalarına duyulan güven değişkenine ek olarak teknolojiye duyulan güven değişkenine vurgu yapmışlardır. Daha önce e-devlet uygulamalarını kullanmış vatandaşlar arasında gerçekleştirilen araştırmada dikkat çeken bir bulgu da vatandaşların e-devlet uygulamalarına teknolojiden daha fazla güven duyuyor olmalarıdır. Yine bir başka araştırmada vatandaşların e-devlet algısı incelenmiş, beklentilerinin neler olduğu tespit edilmeye çalışımıştır. Araştırmada dikkat çeken bir bulgu da vatandaşların e-devlet uygulamalarının kamu hizmetlerine kısmen olumlu bir etki yapacağı eğiliminde olmalarıdır (Şahin, Göküş ve Bayrakçı, 2011). Karaman ilinde gerçekleştirilen bir başka araştırma ise e-devlet uygulamalarının kamu çalışanları ve kamu hizmetleri üzerindeki etkisine odaklanmıştır. (Şahin ve diğerleri, 2013). Araştırma genel olarak vatandaş odaklı e-devlet literatüründen farklı olarak kamu çalışanlarına odaklanması bakımından önem taşımaktadır. Benzer şekilde başka bir araştırmada kamu çalışanlarının e-devlet uygulamalarında karşılaştıkları sorunlar belirlenmeye çalışılmıştır. Araştırma e-devlet kültürünün Türkiye'de henüz yaygınlaşmadığını vurgulamakta bunun temelinde de uzman eleman eksikliği, teknoloji yetersizliği, eğitim sorunu (vatandaş ve kamu çalışanı) ve büyük oranda da bireysel faktörlerin olduğunu vurgulamaktadır. (Sevinç ve Şahin, 2013). Zeren ve arkadaşları (2015) Aydın'da yapmış oldukları bir araştırmada e-belediye hizmetlerine karşı duyarlıı̆̆ı ve hizmetlerden faydalanma derecelerini ölçmüşlerdir. Araştırmada e-belediye hizmetlerinde kaynaklarının yetersiz olduğu, aktif katılımın az ve internet sitelerinin kullanımının kullanıcılar tarafından kolay bulunmadığı vurgulanmıştır. Turan ve Özgen (2009) e-beyanname sisteminin kabulü üzerine yapmış oldukları araştırmada algılanan kullanım kolaylığı, uygunluk, uyumluluk ve algılanan kullanışııı̆ıı kullanım niyetlerini pozitif yönde etkilediği, yakınların etkisi ve kendine güven faktörünün ise kabulü etkilemediği sonucuna ulaşmışlardır. Yapılan bir başka araştırmada ülkemizin e-devlete geçişte karşılaştığı sorunlar, vatandaşların güvenlik endişeleri, e-devlet altyapısının yetersizliği ve internet ile bilgisayar kullanımında eğitim eksikliği şeklinde listelemiştir (Çelen, Çelik ve Seferoğlu, 2011). Ülkemizde e-devlete etki eden faktörlerin teorik olarak incelendiği bir diğer çalışmada ise, e-devlet hizmeti için kurumların altyapılarının yetersiz olduğu ve teknik donanıma sahip nitelikli personele ihtiyaç duyulduğu sonucuna ulaşılmıştır (Naralan, 2008). Ayrıca aynı çalışmada devletin yönetim şeklinin de e-devlete etki eden önemli bir faktör olduğu belirtilmiştir.

Özellikle gelişmekte olan ülkelerde e-devlet adaptasyonunda kaynakların kullanılabilirliği önemli bir konumdadır. Kaynakların kullanılabilirliği elektrik, telefon, bilgisayar, internet ve bilgi ve iletişim teknolojilerinin erişim, hız ve maliyet gibi rekabetçi özelliklerle kullanılabilirliği ve kullanım özgürlüğüdür. Eğerbirülkee-devlet kullanımı için tüm vatandaşlarına gerekli kaynakları eşit olarak dağıtamıyorsa, tüm vatandaşların aynı düzeyde e-devlet adaptasyonu göstermelerini bekleyemez. Bununla birlikte, sayısal uçurum adı verilen bu eşitsizliği azaltmadan, e-devlet kaynaklarının kullanılabilirliğini artırmadan, bir e-devlet sisteminin bütün bileşenlerini kullanılabilir/ erişilebilir hale getirmeden bir e-devlet sistemi başarılı olamayacaktır. Kaynakların kullanılabilirliğinin davranışsal, ekonomik, kültürel, sosyal ve teknolojik boyutları vardır. Bilgisayarın, internetin ve modern bilgi ve iletişim teknolojilerinin olmadığı, vatandaşların ekonomik olarak yoksul ve eğitimsiz olduğu, sosyal ve kültürel olarak yeni teknolojilere aşina olmadığı bir yerde insanlar bir e-devlet sistemini kullanmanın onlar için faydalı olacağına inanmayacaklardır. Dolayısıyla e-devlet adaptasyonu ile kaynakların kullanılabilirliği arasında belirgin bir ilişki vardır (Van Dijk ve diğerleri 2008). Kaynakların kullanılabilirliği bir e-devlet sisteminin kullanılmasına yönelik bir inanç oluşturmakta, bu inanç da bir e-devlet kullanım tutumuna dönüşerek e-devlet adaptasyonunu etkilemektedir (Shareef ve diğerleri 2011). Teknoloji Kabul Modeli (TKM), bir teknolojiyi kullanma tutumunu algılanan kullanım kolaylığı ve algılanan fayda değişkenleri üzerinden açıklamaktadır (Davis, Bagozzi ve Warshaw, 1989; Davis, 1989). Bu davranışsal tutum teknoloji kullanımını dolayısıyla 
da sistemine adaptasyonu etkilemektedir. Rogers (2003); Yeniliğin Yayılımı Teorisi (YYT)'nde bir yeniliğin benimsenme hızını belirleyen unsurlardan birinin algılanan özellikler olduğu belirtmiştir. Bu özellikleri görece yarar, uygunluk, karmaşıklık, denenebilirlik ve gözlemlenebilirlik şeklinde gruplamıştır. Literatürde bu beş değişken bir teknolojik yeniliğe adaptasyonda en ilgili bileşenler olarak gösterilmektedir (Rogers, 2003; Tornatzky ve Klein, 1982). Shareef ve diğerleri (2011) araştırmalarında TKM ve YYT deki bu bileşenlerden algılanan fayda ve görece yararı birleştirerek oluşturdukları "algılanan fonksiyonel fayda" değişkeninin e-devlet adaptasyonunda önemli bir belirleyici olduğunu öne sürmüşlerdir. Algılanan fonksiyonel fayda; vatandaşların geleneksel kamu ofislerini kullanmak yerine, bir e-devlet sistemini kullanmanın maliyet, zaman, verimlilik ve etkinlik açısından genel fonksiyonel faydalarını hem görece hem de mutlak olarak algılama derecesidir. Bu bilgiler doğrultusunda kaynakların kullanılabilirliği ve algılanan fonksiyonel fayda hakkında aşağıdaki hipotezleri ileri sürmek mümkün görünmektedir:

$H_{i}$ : Kaynakların kullanılabilirliği ile e-devlet adaptasyonu arasında pozitif bir ilişki vardır.

$\mathrm{H}_{2}$ : Kaynakların kullanılabilirliği ile algılanan fonksiyonel fayda arasında pozitif bir ilişki vardır.

Literatürdeki bazı araştırmalar müşterileri memnun etmenin dolayısıyla e-devlet hizmetlerinin tekrar kullanımını sağlamanın en önemli yollarından birinin müşteri hizmetleri olduğunu vurgulamaktadır. Hizmet kalitesi farklı organizasyonların hizmet performanslarını farklılaştıran önemli bir etkendir. Davranışsal açıdan değerlendirildiğinde kullanıcılar müşteri hizmetlerinin daha iyi seviyede olduğunu algılarlarsa, e-devlet hizmetini tekrar kullanmalarını sağlamak mümkün olacaktır. Geleneksel kamu binalarındaki yaklaşım e-devlet sisteminden daha farklıdır. Eğer vatandaşlar e-devlet müşteri hizmetlerinin geleneksel kamu binalarında sunulandan daha iyi bir seviyede olduğunu algılarlarsa e-devlet adaptasyonları da kolaylaşacaktır (Shareef ve diğerleri, 2007; Kumar ve diğerleri 2007). Bu araştırmada kullanılan algılanan hizmet yanıtı değiş̧keni de aslında bir kalite bileşenidir. Eğer süreçte bir sorun varsa taraflar her zaman müşteri hizmetlerinin sorunları ilgili bir biçimde çözmesini bekler. Eğer vatandaşlar e-devlet işlemleri sırasında ihtiyaç duydukları anda karşılarında herhangi bir müşteri hizmetleri biriminin olmadığını hisseder, kendilerine ilgili davranılmaz ya da web sitesinin müşteri merkezli politikasını güvenilir bulmazlarsa e-devlet adaptasyonları zorlaşacaktır. Aynı zamanda hizmet alımı için fiziksel bir kamu binası arayışına gireceklerdir (Shareef ve diğerleri, 2009). Bu bilgiler doğrultusunda aşağıdaki hipotezleri ileri sürmek mümkün görünmektedir:

$H_{3}$ : Algilanan hizmet yanitı ile e-devlet adaptasyonu arasında pozitif bir ilişki vardır.

$H_{4}$ : Algılanan hizmet yanıtı ile algılanan fonksiyonel fayda arasında pozitif bir ilişki vardır.

$\mathrm{H}_{5}$ : Algılanan fonksiyonel fayda ile e-devlet adaptasyonu arasında pozitif bir ilişki vardır.

Araştırmanın hipotezleri aşağıdaki model ile test edilecektir.

\section{Şekil 1: Araştırma Modeli}

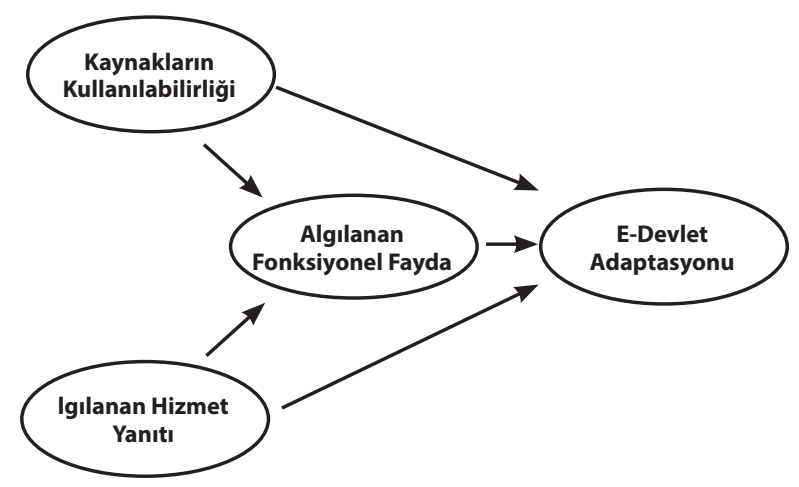

\section{YÖNTEM}

Araştırmanın temel amacı kamusal hizmet dönüşümünün önemli bir göstergesi olan e-devlet adaptasyonunda kaynakların kullanılabilirliği, algılanan fonksiyonel fayda ve algılanan hizmet yanıtı faktörlerinin etkilerinin belirlenmesidir.

Araştırma kapsamında yüz yüze anket yöntemi kullanılmıştır. Araştırma Yalova ili ölçeğinde Nisan 2014- Temmuz 2014 döneminde yapılmıştır. Kolayda örnekleme yöntemi ile mümkün olduğunca farklı sosyo-kültürel ve sosyo-ekonomik özellikteki 600 katılımcıya ulaşılması planlanmıştır. Toplamda 596 katılımcıya anket uygulanmıştır. Araştırma kapsamında yapısal eşitlik modeli kullanılmış, eksik veri olmamasına özellikle dikkat edilmiştir. Hatalı ve eksik doldurulmuş anketler çıkarılmış ve araştırma bulgularının değerlendirilmesi 586 katııımcı üzerinden yapılmıştır. 
Anketin hazırlanmasında uluslararası alanda daha önce test edilmiş ölçeklerden oluşturulmuş ifadeler ve demografik faktörlerin bulunduğu ölçekler kullanılmıştır. Ankette ilk olarak demografik bilgilere yer verilmiştir. Bu kısımda bireylerin cinsiyetleri, eğitim ve gelir durumları, bağıı bulundukları meslek grupları, internet ve bilgisayar kullanma sıklıkları sorulmuştur. Araştırmanın ikinci kısmında ise katılımcılardan düşüncelerini e-devlet adaptasyonunu etkileyen faktörleri belirlemek amacıyla verilen ifadeler hakkında (1) kesinlikle katılmıyorum,(2) katılmıyorum, (3) kararsızım, (4) katılıyorum,(5) tamamen katılıyorum şeklinde derecelendirmeleri istenmiştir. Bu kısımda araştırma modelinde yer alan değişkenlerden kaynakların kullanılabilirliği; Murru (2003), Shareef ve diğerleri (2011), algılanan fonksiyonel fayda; Yoo ve Donthu (2001), Devaraj ve diğerleri (2002), Janda ve diğerleri (2002), Wolfinbarger ve Gilly (2003), Parasuraman ve diğerleri (2005), Tung ve Rieck (2005), Collier ve Bienstock (2006), Fassnacht ve Koese (2006), Kumar ve diğerleri (2007), Shareef ve diğerleri (2007), Shareef ve diğerleri (2011), algılanan hizmet yanıtı ise Janda ve diğerleri (2002), Wolfinbarger ve Gilly
(2003), Parasuraman ve diğerleri (2005), Collier ve Bienstock (2006), Kumar ve diğerleri (2007), Shareef ve diğerleri (2011) tarafından geliştirilmiş ve test edilmiş ölçeklerden derlenen ifadelere yer verilmiştir.

$\mathrm{Bu}$ kısımda araştırmanın sınırlılıklarında da bahsetmek faydalı olacaktır. Literatürde e-devlet adaptasyonuna etki eden kullanım kolaylığı, güven, bilgi kalitesi gibi birçok faktör olmakla birlikte bu araştırmada sadece kaynakların kullanılabilirliği, algılanan fonksiyonel fayda ve algılanan hizmet yanıtı faktörlerinin adaptasyon üzerindeki etkisi incelenmiştir. Bu açıdan bakıldığında bu durum araştırma için bir sınırlııktır. Araştırma için ikinci bir sınırlılık ise araştırma evreninin tümüne ulaşma zorluğu sebebiyle kolayda örnekleme yönteminin seçilmesidir. Örneklemin tüm evreni temsil etmesi olanaksızdır. Bu bağlamda, araştırmayla elde edilen sonuçlarının genelleştirilebilmesi mümkün değildir. Bütçe yetersizliği nedeniyle anketlerin sadece Yalova bölgesinde yapılmış olması, ülke genelinde yapılamayışı araştırmanın bir diğer sınırlılığını oluşturmaktadır.

\section{BULGULAR}

Tablo 1'de örnekleme ait özellikler görülmektedir.

Tablo 1: Örneklem Özellikleri

\begin{tabular}{|c|c|c|c|c|c|c|c|c|}
\hline \multirow{2}{*}{ Cinsiyet } & \multirow{2}{*}{ Yüzde } & \multirow{2}{*}{ Gelir Durumu } & \multirow{2}{*}{ Yüzde } & \multirow{2}{*}{$\begin{array}{l}\text { İnt. ve Bil. } \\
\text { Kullanımı }\end{array}$} & \multicolumn{2}{|c|}{ Yüzde } & \multirow{2}{*}{ Eğitim } & \multirow{2}{*}{ Yüzde } \\
\hline & & & & & İnternet & Bilgisayar & & \\
\hline Erkek & 55.7 & 1000 TL den az & 27.4 & 1 yıldan az & 2.7 & 1.9 & İlkokul & 1.7 \\
\hline \multirow[t]{5}{*}{ Kadın } & 44.3 & $1000-1500 \mathrm{TL}$ & 19.5 & $1-3$ yıl & 5.7 & 4.1 & Lise & 5.0 \\
\hline & & $1501-2500 \mathrm{TL}$ & 27.9 & $4-6 \mathrm{yıl}$ & 18.5 & 13.2 & Ortaokul & 25.7 \\
\hline & & $2501-3500 \mathrm{TL}$ & 18 & 7-9 yıl & 25.2 & 24.1 & Lisans & 57.2 \\
\hline & & $3500-5000 \mathrm{TL}$ & 4.3 & $10 \mathrm{yll}+$ & 47.3 & 56 & Y.lisans & 9.6 \\
\hline & & $5000 \mathrm{TL}+$ & 2.9 & Hiç kullanm. & 7 & 7 & Doktora & 0.9 \\
\hline
\end{tabular}

Şekil 1'de görselleştirilen araştırma hipotezlerinin testi için Anderson ve Gerbing'in (1988) iki adımlı yaklaşımı kullanılmıştır. Buna göre öncelikle doğrulayıcı faktör analizi gerçekleştirilerek ölçüm modelinin geçerlilik ve güvenilirliği test edilmiş, daha sonra ise araştırma hipotezleri doğrultusunda oluşturulan yapısal model test edilmiştir.

Araştırma modelinde yer alan değişkenlere ait ölçüm modelinde çok sorulu yansıtmalı ölçek özelliği taşıyan "Algılanan Hizmet Yanıtı", "Algılanan Fonksiyonel Fayda" ve "E-Devlet Adaptasyonu", ile oluşturmalı ölçek özelliği taşıyan "Kaynakların Kullanılabilirliği" ölçeklerine yer verilmiştir. Kaynakların kullanılabilirliği ölçeği, oluşturmalı yapısı nedeniyle, modele dahil edilmeden önce ölçekte yer alan dört sorunun aritmetik ortalaması alınarak kaynak kullanımı miktarına yönelik ortalama bir değer elde edilmiş ve böylece tek maddeli bir kaynak kullanımı değişkeni oluşturulmuştur. Tek maddelik bu değişkenin ölçüm modeline gizli bir değişken olarak eklenebilmesi için tek maddelik değişkenin hata varyansı değişkene ait varyansın yüzde onuna sabitlenmiştir (Yılmaz ve diğerleri 2005). 
Kurulan bu ölçüm modeli (Şekil.1) en yüksek olabilirlik (maximum likelihood) hesaplama tekniği kullanılarak test edilmiştir. Doğrulayıcı faktör analizi sonuçları $\left(\mathrm{X}_{(184)=} 1261,541, \mathrm{p}<.01, \mathrm{CMIN} / \mathrm{df}=6.856 \mathrm{GFI}\right.$ $=.82 \mathrm{NFI}=.83 \mathrm{CFI}=.85 \mathrm{RMSEA}=0.10)$ ölçüm modeli ile data arasındaki uyumun yetersizliğine işaret etmiştir.

Şekil 2. Ölçüm Modeli

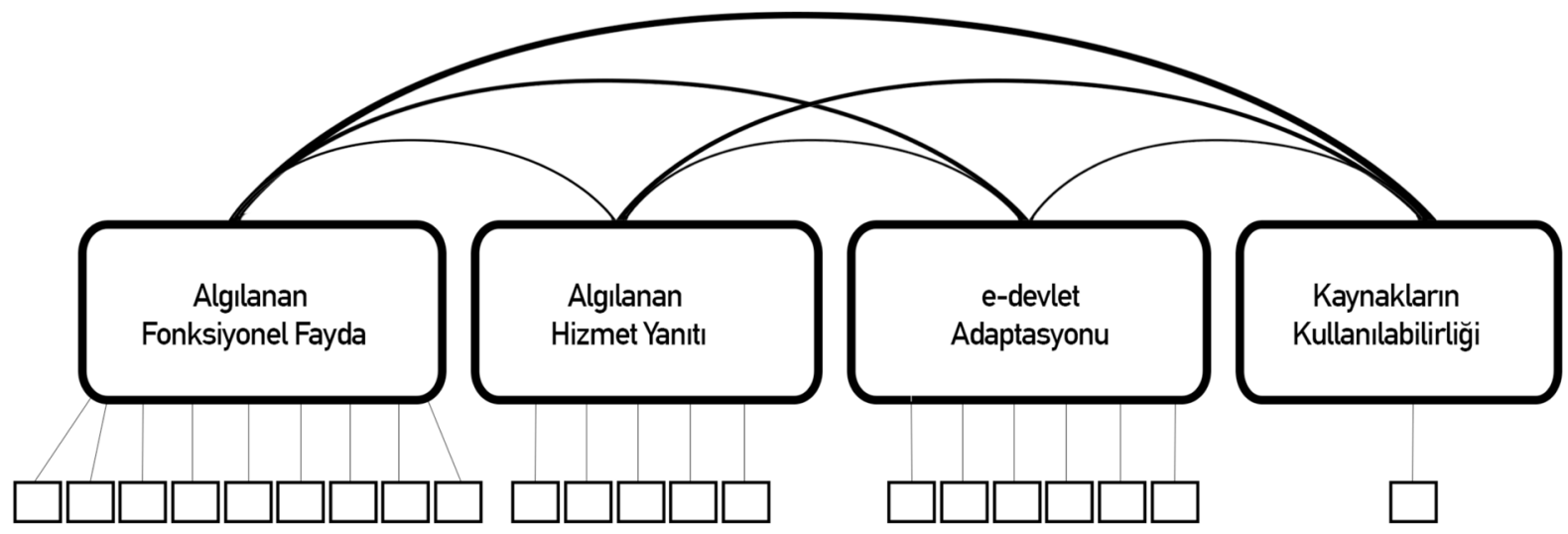

Maddelere ait faktör yükleri, standart hata kovaryans katsayıları ve modifikasyon göstergeleri incelenerek sorunlu maddeler belirlenmiştir. Ölçüm modelinde algılanan fonksiyonel fayda değişkeninin ölçümünde kullanılan dokuz sorudan dördü, düşük ve anlamsız ( $p>0.05$ ) faktör yükleri ve/veya diğer değişkenlere ait soruların hata terimleri ile gösterdikleri yüksek korelasyon sebebi ile elenmiş (AFF 6,4,3,2), birbirlerinin meydana gelmesinde etkili olduğu sonucuna varılan AFF7 ile AFF8 maddelerine ait hata terimleri arasında ise korelasyona izin verilmiştir.

Benzer şekilde algılanan hizmet yanıtı faktörü içinde yer alan AHT5 değişkeni hata değerinin diğer gözlenen değişkenlerin hata değerleriyle yüksek kovaryans değerine sahip olması nedeniyle faktörden çıkarılmıştır. Son olarak faktör yüklerinin düşüklüğü ve hata kovaryanslarının yüksekliği nedeni ile 6 soru ile ölçümlenen adaptasyon değişkenine ait 3 madde ölçüm modelinden çıkarılmış( ADP 4, 5, 6) ölçüm modeline son hali verilerek doğrulayıı faktör analizi yenilenmiştir. Ki-kare istatistiğinin muhtemelen örneklem hacmine bağlı olarak anlamlı çıkmış olmasına rağmen $(X 2,59,=187,010, p<.01)$ elde edilen uyum indeksleri $(\mathrm{CMIN} / \mathrm{df}=3.710 \mathrm{GFI}=.95 \mathrm{NFI}=.95$ $\mathrm{CFI}=.97$ RMSEA $=0.60$ ) data ile model arasında tatmin edici bir uyuma işaret etmiştir. Maddelere ait faktör yükleri ile ölçüm modeli uyum iyiliği değerleri Tablo 2'de verilmiştir.

Ölçeklerin güvenilirliklerin testi için hesaplanan bileşik güvenilirlik (C.R) değerlerinin tüm değişkenler için kritik seviye olan .60'ın (Bagozzi ve Yi, 1988), Cronbach alfa katsayılarının ise Nunnaly (1978) tarafından belirtilen kritik nokta olan .70'in üzerinde olduğu görülmüş ve ölçeklerin güvenilir olduğu sonucuna varılmıştır (Berthon ve diğ., 2005). 
Tablo 2: Maddelere a Ait Faktör Yükleri; Değişkenlere Ait Cronbach Alfa (a) , Bileşik Güvenilirlik (CR) ve Ortalama Açıklanan Varyans Katsayıları (AVE).

\begin{tabular}{|c|c|}
\hline & Faktör Yükleri \\
\hline \multicolumn{2}{|l|}{ Algılanan Fonksiyonel Fayda (C.R. $=.88, A V E=0.60, a=0.88)$} \\
\hline AFF1 : E-Devlet web sitelerini ihtiyacım olan her yerde kullanabilmek önemlidir. & $.686^{* *}$ \\
\hline AFF5 :E-Devlet web siteleri işlemleri daha hızlı yerine getirmede yardımcı olur. & $.784^{* *}$ \\
\hline AFF7 : E-Devlet web sitelerini kullanmak genel verimliliği arttırır & $.849^{* *}$ \\
\hline AFF8 : E-Devlet web siteleri kullanılarak işlemler daha kolay gerçekleştirilebilir & $.813^{* *}$ \\
\hline AFF9: E-Devlet web siteleri daha doğru kararlar verilmesine yardımcı olur & $.735^{* *}$ \\
\hline \multicolumn{2}{|l|}{ Algılanan Hizmet Yanıtı (C.R. $=.81, \mathrm{AVE}=.52, \mathrm{a}=0.80)$} \\
\hline AHT1:E-Devlet web siteleri beni değerli bir müşteri olarak hatırlar ve tanır. & $.712^{* *}$ \\
\hline AHT2 : E-Devlet web sitelerinin müşteri hizmetleri benim özel ihtiyaçlarımı giderir. & $.764^{* *}$ \\
\hline AHT3 : Herhangi bir sorunla karşılaştığımda E-Devlet web siteleri hızlıca düzeltici aksiyon alır & $.786^{* *}$ \\
\hline AHT4 : Online müşteri hizmetlerine 24 saat ulaşabilirim. & $.601^{* *}$ \\
\hline \multicolumn{2}{|l|}{ E-devlet Adaptasyonu (C.R. $=0.83, \mathrm{AVE}=0.62, \mathrm{a}=0.83$ ) } \\
\hline ADP1: E-Devlet web sitelerini bilgi edinmek ve form indirmek için kullanıyorum & $.725^{* *}$ \\
\hline ADP2: Bilgi edinmek ve form indirmek için gelecekte de E-Devlet web sitelerini kullanmak isterim. & $.810^{* *}$ \\
\hline $\begin{array}{l}\text { ADP3 : Bilgi edinmek ve form indirmek için E-Devlet web sitelerini kullanmayı akrabalarıma ve } \\
\text { arkadaşlarıma öneririm. }\end{array}$ & $.818^{* *}$ \\
\hline \multicolumn{2}{|l|}{ Kaynakların Kullanılabilirliği (Oluşturmalı ölçek) (C.R., AVE ve a katsayısı hesaplanılmadı) } \\
\hline $\begin{array}{l}\text { KK1:Evde yeterli bilgisayar teknolojisine sahibim. } \\
\text { KK2: İşyerimde yeterli bilgisayar teknolojisine sahibim. } \\
\text { KK3:Evde her zaman internet bağlantısına sahibim. } \\
\text { KK4 :Işsyerimde her zaman internet bağlantısına sahibim }\end{array}$ & \\
\hline
\end{tabular}

Soruların faktör yükleri incelendiğinde tüm soruların ait oldukları faktörlere yüksek ve anlamlı faktör yükleriyle yüklendiği ve dolayısıyla yakınsama geçerliliğinin sağlandığı görülmüştür. Ayrıca tüm ölçeklere ait açıklanan varyans katsayılarının .50'nin üzerinde olması yakınsama geçerliliğinin diğer bir göstergesidir (Fornell ve Lacker, 1981). Her bir faktör için hesaplanan ortalama açıklanan varyans değerlerinin, faktörlerin diğer tüm faktörlerle paylaştığı varyanstan (Tablo 3'te sunulan korelasyon katsayılarının karesinden) yüksek olduğu gözlenmiş bu sebeple değişkenlerin ayrışma geçerliliği şartını da sağladığı anlaşılmıştır.

Tablo 3: Değişkenler Arası Korelasyon Katsayıları

\begin{tabular}{|l|c|c|c|c|}
\hline Faktörler & $\mathbf{1}$ & $\mathbf{2}$ & $\mathbf{3}$ & $\mathbf{4}$ \\
\hline 1- Kaynakların Kullanılabilirliği & 1.00 & & & \\
\hline 2- Fonksiyonel Fayda & $0,30^{* *}$ & 1.00 & & \\
\hline 3- Hizmet Yanıtı & $0,11^{*}$ & $0,60^{* *}$ & 1.00 & \\
\hline 4- E-devlet Adaptasyonu & $0,32^{* *}$ & $0,55^{* *}$ & $0,75^{* *}$ & 1.00 \\
\hline
\end{tabular}

** $p<.01, * p<.05$ 


\section{Hipotez Testi}

Araştırma hipotezlerinin testi için gizil değişkenler ile oluşturulan yapısal model, en yüksek olabilirlik (maximumlikelihood) hesaplama tekniği kullanılarak test edilmiștir. Ölçüm modeline bezer şekilde örneklem hacmine bağlı olarak Ki-kare istatistiğinin anlamlı çıkmasına rağmen (x2(60)
$=192,435 \quad \mathrm{p}<.01$ ) uyum iyiliği indeksleri makul seviyede bir uyuma işaret emektedir $(X 2 / d f=3.207$, $\mathrm{GFI}=.95, \mathrm{NFI}=.95, \mathrm{CFI}=0.96 \mathrm{RMSEA}=0.06$ ). Modelin genel olarak değerlendirilmesinin ardından araştırma hipotezlerinde ileri sürülen ilişkilere dair analiz sonuçları ise Tablo 4'de sunulmuştur.

Tablo 4: Hipotez testi sonuçları

\begin{tabular}{|l|c|c|c|c|c|c|}
\hline Hipotezler & Katsayı & $\begin{array}{c}\text { Std. } \\
\text { Katsayı }\end{array}$ & $\begin{array}{c}\text { Std. } \\
\text { Hata }\end{array}$ & $\mathbf{t}$ & p & Sonuç \\
\hline $\mathrm{H}_{1}:$ Kaynakların Kullanılabilirliği $\Rightarrow$ E-devlet Adaptasyonu & .092 & .119 & .030 & 3.036 & .01 & Kabul \\
\hline $\mathrm{H}_{2:}$ Kaynakların Kullanılabilirliği $\Rightarrow$ Algılanan Fonksiyonel Fayda & .22 & .253 & .035 & 6.305 & .01 & Kabul \\
\hline $\mathrm{H}_{3}:$ Algılanan Hizmet Yanıtı $\Rightarrow$ E-devlet Adaptasyonu & .186 & .162 & .061 & 3.07 & .01 & Kabul \\
\hline $\mathrm{H}_{4}:$ Algılanan Hizmet Yanıtı $\Rightarrow$ Algılanan Fonksiyonel Fayda & .749 & .582 & .073 & 10.213 & .01 & Kabul \\
\hline $\mathrm{H}_{5}:$ Algılanan Fonksiyonel Fayda $\Rightarrow E-$ devlet Adaptasyonu & .553 & .62 & .055 & 10.112 & .01 & Kabul \\
\hline $\mathrm{R}^{2}$ (Algılanan fonksiyonel Fayda) $=.40 ; \mathrm{R}^{2}$ (e-devlet kabulü) $=.58$ & & & & & & \\
\hline
\end{tabular}

\section{SONUÇ}

Gelişen ve değişen bilgi ve iletişim teknolojileriyle birlikte vatandaş ve devletin beklentileri teknolojik gelişmelerle doğru orantılı olarak değişmiştir. Bu değişimle beraber devlet birçok hizmeti elektronik ortamda sunarak etkin bir dijital altyapıya geçiş sağlamıştır. Yapılan bu yatııımların etkinliğinin önemi kadar vatandaşların bu hizmetlerden haberdar olmaları ve hizmetlere erişimleri de büyük önem arz etmektedir. Bu araştırma ile daha önce özellikle gelişmiş birçok ülkede test edilmiş olan e-devlet kabulüne etki eden faktörlere ait ölçeklerin Türkiye gibi gelişmekte olan bir ülkede bölgesel ölçekte uygulanmış ve sonuçlar tartışılmıştır. Bu doğrultuda e-devlet kabulüne etki edebilecek önemli görülen faktörlerin bulunduğu bir araştırma modeli oluşturulmuş bu araştırma modelinin geçerlilik ve güvenilirliğinin test edilmesi amaçlanmıştır. Modelde yer alan kaynakların kullanılabilirliği, algılanan fonksiyonel fayda ve algılanan hizmet yanıtı faktörlerinin e-devlet adaptasyonunda pozitif bir etki oluşturdukları tespit edilmiştir. E-devlet adaptasyonuna etki eden faktörlerden kaynakların kullanılabilirliği faktörünün belirgin bir şekilde gelişmiş ve gelişmekte olan ülkeler arasında farklılık gösterdiği gibi ülke içerisinde bölgeler arasında da farklılık göstermektedir. Geliş̧miş ülkelerde kaynakların kullanılabilirliği, altyapı yatırımları ve teknoloji yayılımının tüm bölgelere aynı oranda yapıldığı göz önüne alındığında aynı durumun gelişmekte olan ülkeler için geçerli olmadığı ifade edilebilir. Gelişmekte olan ülkelerde nüfusun daha az yoğun olduğu bölgelerde yatırımların yetersiz olması kullanıcılar açısından kaynaklara erişimi ve kullanımı olumsuz yönde etkilemektedir.

Bu açıdan bakıldığında araştırma kapsamında yer alan Yalova bölgesi kaynaklara erişim düzeyi dikkate alındığında ülke ortalamasının üzerinde olan Marmara bölgesinde yer almaktadır. Bu durumunda kaynakların kullanımının e-devlet adaptasyonunu etkilediği görülmektedir. Gelişmişülkelerde genellikle tüm kullanıcıların kaynaklara kolaylıkla erişebildiği göz önüne alındığında bu faktör ile e-devlet kabulü arasında bir ilişki olduğu söylenebilir. Uluslararası literatürde yer alan gelişmiş ülkeler örnekleminde yapılan araştırmalarda bu etki araştırmacılar tarafından vurgulanmıştır (Shareef, 2011).

Ülkemizde yapılan çalışmalarda ise teknik alt yapı faktörünün gelişmişlik düzeyiyle doğrudan ilişkili olduğu ifade edilerek kaynaklara erişim düzeyinin artırılması gerektiği konusuna vurgu yapılmıştır (Naralan, 2008). Ayrıca kaynakların kullanılabilirliği, algılanan fonksiyonel faydayı pozitif yönde etkilemektedir. Vatandaşların bilgi ve iletişim teknolojilerini kullanarak zamandan ve mekândan bağımsız hareket etmeleri, istedikleri zaman hizmetlere ulaşabilmeleri verimliliği ve fonksiyonelliği pozitif yönde etkilemektedir. Bu bağlamda kaynakların kullanılabilirliği e-devlet adaptasyonunu doğrudan etkilemekte, fonksiyonel fayda üzerinden de e-devlet adaptasyonunu etkilemektedir. 
Kullanıcıların e-devlet ihtiyaç duydukları bilgi ve dokümanlara hızlı erişim sağlayabilmeleri, bir sorunla karşılaştıklarında etkin çözümler üretilmesi, daha önce sisteme dahil olan kullanıcıların sistem tarafından hızlıca tanınabilmesi, kullanıcıların e-devlet hizmetlerinden memnuniyetlerini artırmakta, e-devlet hizmetlerini sıklıkla kullanmalarını sağlamakta ve aldıkları hizmete e-devlet üzerinden tekrar erişimlerini teşvik etmektedir. Algılanan hizmet yanıtı olarak ifade edilen bu durum e-devlet adaptasyonunu pozitif yönde etkilemektedir. Hizmet alt yapısının sorunsuz ve başarılı bir şekilde kurulması ve yürütülmesi ülkelerin gelişmişlik düzeylerine göre farklılık gösterebilmektedir. Devlet hizmetlerinin elektronik ortamlardan yapılması sonrasında oluşan memnuniyet ve bu hizmetlere erişimin tekrar e-devlet üzerinden tercih edilmesi zamandan tasarruf sağlamakta, maliyetleri azaltmakta ve verimliliği artırmaktadır. Bu duruma bağlı olarak algılanan hizmet yanıtı fonksiyonel faydayı pozitif yönde etkilemektedir. Benzer şekilde literatürde yer alan çalışmalarda yetersiz altyapı ile hizmetin sunulmaya çalışııması kullanıcıları e-devlet hizmetlerinden uzaklaştırdığı ve yapılan çalışmaların elde edilen fayda beklentisini karşılamadığı ifade edilmiştir (Acar ve Kumaş 2008). Tüm bunlara ek olarak algılanan fonksiyonel fayda e-devlet üzerinden yeniden hizmet alımını ve fonksiyonelliği artırmakta ve e-devlet adaptasyonunu kolaylaştırmaktadır. Literatürde yer alan benzer araştırmalarda da kullanıcıların e-devletin beraberinde getirdiği avantajları benimsedikleri ve önemli buldukları, bunun da kullanıcıların tutumlarını etkilediği vurgulanmıştır (Tüzel 2003). Dolayısıyla bu çalışmanın bulgularıyla literatürdeki mevcut araştırmanın bulgularının örtüştüğü söylenebilir.

$\mathrm{Bu}$ çalışmanın kapsamı ve bulguları dikkate alındığında konu ile ilgili gelecek araştırmalar için birkaç öneri sıralanabilir. İlk olarak araştırma modelinde test edilen e-devlet adaptasyonunu etkileyen faktörlerle birlikte, literatürde kabul görmüş diğer faktörler eklenerek, çeşitli aracı değişkenlerin etkilerini de dikkate alarak daha geniş bir model önerisi oluşturulabilir. Ayrıca araştırmanın Türkiye'nin farklı illerinde tekrarlanması sonuçların geçerliliğinin artııılması açısından önemli katkılar sağlayacaktır.

\section{KAYNAKLAR}

Acar, M., \& Kumaş, E. (2008). Türkye'nn dönüşüm sürecnde anahtar br mekanzma olarak e-devlet, e-dönüşüm ve entegrasyon standartları. 2. Ulusal iktisat Kongresi.

Alomari, M.K. (2014). Alomari, M. K. (2014). Discovering citizens reaction toward e-government: factors in e-government adoption. JISTEM - Journal of Information Systems and Technology, 11, 5-20.

Al-zoubi, M., Sam, T.L., Eam, L.H. (2011). E-Government Adoption Among Businesses in Jordan. AcademicResearch International, 1(1), 141-156.

Andersen, K. V., Henriksen, H. Z. (2005). The first leg of e-government research: Domains and application areas 1998-2003. International Journal of Electronic GovernmentResearch, 1(14), 26-44.

Anderson, J. C., \&Gerbing, D.W. (1988). Structural equation modeling in practice: A review and recommended two step aproach. Psychological Bulletin, 103(3), 411-423.

Bagozzi, R. P., \&Yi, Y. (1988). On the evaluation of structural equation models. Journal of the Academy of Marketing Science, 16(1), 74-94.

Bayrakçı, Erdal; Şahin, Ali ve Taşpınar, Yasin, "The Relationship between Trust in Government, Trust in E-Government Website and Intention to Continue Using E-Government Implementations", International Institute of SocialandEconomicSciences 6th International Academic Conference, 23-26 Haziran, 2013, Bergen, Norveç.
Berthon, Pierre, Michael Ewing ve LiLian Hah (2005), Captivating Company: Dimensions of Attractiveness in Employer Branding, International Journal of Advertising, 24(2), 151-172.

Carter, L. (2008). E-government diffusion: a comparison of adoption constructs. Transforming Government: People, Process and Policy, 2(3), 147-161.

Carter, L., Belanger, F. (2005). Theutilization of e-governmentservices: Citizentrust, innovation and acceptance factors. Information Systems Journal, 15(1), 5-25.

Carter, L., Weerakkody, V. (2008). E-government adoption: A cultural comparison. Information Systems Frontiers, 10(4), 473-482.

Chen, Y., Chen, H. M., Ching, R. K. H., \& Huang, W. W. (2007). Electronic Government Implementation: A Comparison between Developed and Developing Countries. International Journal of Electronic Government Research, $3(2), 45-49,51-56,58-61$.

Collier, J. E., \& Bienstock, C. C. (2006). Measuring service quality in e-retailing. Journal of Service Research, 8(3), 260-275.

Çelen, Fatma Kübra, Aygül Çelik, ve Süleyman Sadi Seferoğlu. «Türkiye'deki e-Devlet Uygulamalarının Değerlendirilmesi.» Akademik Bilişim Dergisi, İnönü Üniversitesi, Malatya, Türkiye (9-1 :(2011. 
Davis, F. D. (1989). Perceived Usefulness, Perceived Ease of Use, and User Acceptance of Information Technology. MIS Quarterly, 13(3), 319-340.

Davis,F. D. (1989). Perceived Usefulness, Perceived Ease of Use, and User Acceptance of Information Technology.MIS Quarterly. 13(3), 319-340.

Davis, F. D., R. P. Bagozzi ve P. R. Warshaw. (1989). User Acceptance of Computer Technology: A Comparison of Two Theoretical Models. Management Science. 35(8), 982-1003.

Davison, R., Wagner, C., \&Ma, L. (2005). From government to e-government: A transition model. Information Technology and People, 18(3), 280-299.

Devaraj, S., Fan, M., \&Kohli, R. (2002). Antecedents of B2C Channel Satisfaction and Preference: Validating E-commerceMetrics. Information Systems Research, 13(3), 316-333.

Dwivedi, Y. K. (2009). An analysis of e-government research published in Transforming Government: People, Process and Policy (TGPPP). Transforming Government: People, Process and Policy, 3(1), 7-15.

Elbahnasawy, N. G. (2014). E-Government, Internet Adoption and Corruption: An Empirical Investigation. World Development, 57, 114-126.

Ertaş, H. (2014) "Yönetişim e-devlet bağlamında kamu yönetiminin dönüşümü", Teoriden uygulamaya e-devlet, Editörler: Ali Şahin, Erhan Örselli Nobel Yayın Dağıtım, Ankara.

Evans, D.,Yen, D. C. (2006). E-government: Evolving relationship of citizens and government, domestic, and international development. Government Information Quarterly, 23(2), 207-235.

Fassnacht, M., Koese, I. (2006). Quality of Electronic Services: Conceptualizing and Testing a Hierarchical Model. Journal of Service Research, 9(1), 19-37.

Foley, P. (2005). Therealbenefits, beneficiaries and value of e-government. Public Money \& Management, January, 4-6.

Fornell, C., \&Larcker, D. F. (1981). Evaluating structural equation models with unobservable variables and measurement error. Journal of Marketing Research, 18(1), 39-50.

Gupta, M. P., \&Jana, B. (2003). e-Government evaluation: A frameworkand a casestudy. Government Information Quarterly, 20(4), 365-387.

Halchin, L. E. (2004). Electronic government: Government capability and terrorist resource. Government Information Quarterly, 21, 406-419.

Heeks, R. (2005). e-government as a Carrier of Context. Journal of PublicPolicy, 25(1),51-74.

Heeks, R., Bailur, S. (2007).Analyzing e-government research: Perspectives, philosophies, theories, methods, andpractice. Government Information Quarterly, 24(2), 243-265.
Janda, S., Trocchia, P. J., \&Gwinner, K. P. (2002). Consumer perceptions of Internet retail service quality. International Journal of Service Industry Management, 13(5), 412-431.

Joseph, R. C. (2013). A structuredanalysis of e-government studies: Trends and opportunities. Government Information Quarterly, 30(4), 435-440.

Kumar, V., Mukerji, B., Butt, I., \&Persaud, A. (2007). Factors for successful e-government adoption: A conceptual framework. The Electronic Journal of e-Government, 5(1), 63-76.

Lau, T.Y., Aboulhoson, M., Lin, C. ve Atkin, D. J. (2014) Adoption of e-government in three Latin American countries: Argentina, Brazil and Mexico. Telecomunications Policy, 32, 88-100.

Lean, OK., Zailani, S., Ramayah, T., Fernando, Y. (2009). Factors influencing intention to use e-government services among citizens in Malaysia. International Journal of Information Management, 29(6), 458-475.

Lu, L., Zhu, G., \& Chen, J. (2004, September). An infrastructure for e-government based on semantic Web services. In Services Computing, 2004.(SCC 2004). Proceedings. 2004 IEEE International Conference on (pp. 486-483). IEEE.

Luna-Reyes, L. F., Gil-Garcia, J. R., Romero, G. (2012). Towards a multidimensional model for evaluating electronic government: Proposing a more comprehensive and integrative perspective. Government Information Quarterly ,29(3), 324-334.

Murra Maria Elena (2003), "E-government: from real to virtual democracy", Boston University, http://workspace. unpan.org/sites/Internet/stellent/UNPAN011094.pdf OECD, e-Government Studies: Turkey 2007.

Naralan A., (2008). E-Devlet ve Algilanisi Uzerine Bir Arastirma, Ankara: Imaj Kitabevi.

Naralan, Abdullah. (2008). "E-Devlet'e Etki Eden Faktörler." Atatürk Üniversitesi Sosyal Bilimler Enstitüsü Dergisi 12.2.

Nawafleh, S. A., Obiedat, R. F., \& Harfoushi, O. K. (2012). E-Government between Developed and Developing Countries. International Journal of Advanced Corporate Learning, 5(1), 8-13.

Odabaş, Hüseyin. E-devlet sürecinde elektronik belge yönetimi. Türk Kütüphaneciler Derneği İstanbul Şübesi, 2009.

Parasuraman, A., Zeithaml, V. A., \&Malhotra, A. (2005). E-SQUAL a multiple-item scale for assessing electronic service quality. Journal of Service Research, 7(3), 213-233.

Rehman, M., Esichaikul, V., \& Kamal, M. (2012). Factors influencing e-government adoption in Pakistan. Transforming Government: People, Process and Policy, 6(3), 258-282.

Rhoda, C. J. (2013). A structured analysis of e-government studies: Trends and opportunities. Government Information Quarterly,30(4), 435-440. 
Rogers, E. (2003). Diffusion of Innovations. New York: FreePress.

Rokhman, A. (2011). E-government Adoption In Developing Countries; the Case of Indonesia. Journal of EmergingTrends in Computing and Information Sciences, 2(5), 228

Sang, S., Lee, J. D., \& Lee, J. (2010). E-government adoption in Cambodia: a partial least squares approach. Transforming Government: People, Process and Policy, 4(2), 138-157.

Sevinç, İ., Şahin, A. (2013). "Kamu Çalışanlarının E-Devlet Uygulamalarında Karşılaştıkları Sorunların Belirlenmesine Yönelik Karaman Ilinde Bir Araştırma." Süleyman Demirel Üniversitesi İktisadi ve İdari Bilimler Fakültesi Dergisi, 18(2).

Shareef, M. A., Kumar, U., Kumar, V. (2007). Developing fundamental capabilities for successful e-government implementation. Proceedings of ASAC Conference, Ottawa.

Shareef, M. A., Kumar, U., Kumar, V., \&Dwivedi, Y. K. (2009). Identifying critical factors for adoption of e-government. Electronic Government, an International Journal, 6(1), 70-96.

Shareef, MA., Kumar, V., Kumar, U., Dwivedi, YK. (2011). e-Government Adoption Model (GAM): Differing service maturitylevels. Government Information Quarterly, 28(1),17-35.

Snead, J. T., Wright, E. (2014). E-government research in the United States. Government Information Quarterly, 31(1), 129-136.

Sobacı M. Z.. (2012): E-Devlet: Kuramsal Bir Bakış. Kitapta bolum: E-devlet Kamu yonetimi Ve Teknoloji İliskisinde Guncel Gelismeler. Editorler: Mehmet Zahid Sobaci, Mete Yildiz 293-322, Nobel Yayinevi.

Şahin, A., «Kamu Çalışanlarının E-Devleti Algılayış Biçimleri: Beklentiler ve Sorunlar", Kamu Yönetimi Yazıları, Editörler: Bilal Eryılmaz, Musa Eken ve M. Lütfi Şen, 514-541, Nobel Yayın Dağıtım, Ankara, 2007.

Şahin, A., (2007) "Kamu Çalışanlarının E-Devleti Algılayış Biçimleri: Beklentiler ve Sorunlar", Kamu Yönetimi Yazıları, Editörler: Bilal Eryılmaz, Musa Eken ve M. Lütfi Şen, 514-541, Nobel Yayın Dağıtım, Ankara

Şahin, A., Bayrakçı, E., Göküş, M, (2014) «Vatandaşların e-devlet uygulamalarına yönelik algısı", Teoriden uygulamaya e-devlet, Editörler: Ali Şahin, Erhan Örselli s59 Nobel Yayın Dağıtım, Ankara.

Şahin, Ali; Göküş, Mehmet ve Bayrakçı, Erdal. "Vatandaşların E-Devlet Algısı", Kamu Yönetimi Formu IX, 19-21 Ekim 2011, Gazi Üniversitesi.

Şahin, Ali; Sevinç, İsmail; Bayrakçı, Erdal ve Erkış, İbrahim Uğur, "E-Government Implementations and its Effects on Public Services from the Perspective of Public Officials", International Institute of Socialand Economic Sciences 6th International Academic Conference, 23-26 Haziran, 2013, Bergen, Norveç.
Taşpinar Yasin; Şahin, Ali; Göküş, Mehmet ve Ceran, Yunus, "TheRelationshipbetween Trust Propensity, Trust in Technology and Trust in E-Government Implementations: The Case of Konya", International Institute of Socialand Economic Sciences 7th International Academic Conference, 1-4 Eylül, 2013, Prag, Çek Cumhuriyeti.

Tornatzky, L. G. ve K. J. Klein. (1982). Innovation Characteristics and Innovation Adoption-Implementation: A Meta-Analysis of Findings. IEEE Transactions on Engineering Management. 29(1), 28-45.

Tung, L. L., \&Rieck, O. (2005). Adoption of electronic government services among business organizations in Singapore. Journal of Strategic Information Systems, 14, 417-440.

Turan, A. H., \& Özgen, F. B. (2011). Türkiye'de e-beyanname sisteminin benimsenmesi: geliştirilmiş teknoloji kabul modeli ile ampirik bir çalışma. Doğuş Üniversitesi Dergisi, 10(1), 134-147.

Tüzel, A. (2003). E-devlet'in Yararları ve Vatandaşın Beklentileri: İ. t. ü. İşletme Fakültesinde Bir Alan Araştırması (Yüksek lisans tezi, Fen Bilimleri Enstitüsü).

Van Dijk, Jan A. G. M., Peters, O., \&Ebbers, W. (2008). Explaining the acceptance and use of government internet services: A multivariateanalysis of 2006 survey data in the Netherlands. Government Information Quarterly, 25(3), 379-39.

Venkatesh, V., Morris, M.G., Davis G.B., ve Davis, F.D. (2003). User Acceptance of Information Technology: Toward A UnifiedView. MIS Quarterly, 27(3), 425-478.

Wolfinbarger, M., \&Gilly, M. C. (2003). eTailQ: dimensionalizing, measuring and predicting etail quality. Journal of Retailing, 79(3), 183-198.

Yılmaz C., Sezen B., Özdemir Ö. (2005). Joint and interactive effects of trust and (inter) dependence on relational behaviors in long-term channel dyads. Industrial Marketing Management, 34(3), 235-248.

Yoo, B., Donthu, N. (2001). Developing a scale to measure the perceived quality of an internet shopping site (sitequal). QuarterlyJournal of Electronic Commerce, 2(1), 31-46.

Zeren, H. E., Sebetçi, Ö., \& Koçak, Y. (2015). e-devlet ve e-belediye hizmetleri çerçevesinde aydın halkının katılma duyarııı̆ının ölçülmesi. Kafkas Üniversitesi İktisadi ve İdari Bilimler Fakültesi Dergisi,6(9).

Zhang, H., Xu, X., Xiao, J. (2014) Diffusion of e-government: A literature review and directions for future directions. Government Information Quarterly, 31, 631-636.

Zhao, F., \& Khan, M. S. (2013). An Empirical Study of E-Government Service Adoption: Culture and Behavioral Intention. International Journal of Public Administration, 36(10), 710-722. 